\title{
Studies on the Origin of Testosterone in the Urine of Normal Adult Subjects and Patients with Various Endocrine Disorders *
}

\author{
Alvro M. Camacho $\dagger$ and Claude J. Migeon \\ (From the Endocrine Clinic of the Department of Pediatrics, Johns Hopkins University \\ School of Medicine, Baltimore, Md.)
}

We have recently described a procedure for the isolation of testosterone ${ }^{1}$ from human urine after $\beta$-glucuronidase hydrolysis, indicating that it was conjugated with glucuronic acid (1). We also reported on the urinary excretion of testosterone in adult subjects and in patients with endocrine disorders.

The concentration of 17 -ketosteroids in biological fluids is commonly used as an index of virilization. Frequently, however, there is no correlation between the degree of virilism observed in patients and levels of the 17-ketosteroids in blood or urine. Testosterone could be produced by such patients in amounts sufficient to cause virilization without appreciably increasing the levels of 17-ketosteroids in biological fluids.

If a relatively constant quantity of testosterone produced in the body is converted to testosterone glucuronide and if other secreted steroids are not converted in significant amounts to testosterone glucuronide, then its urinary levels should reflect the production of testosterone and correlate better with the degree of virilism.

The purpose of this study, therefore, was to determine the constancy of conversion of testosterone to its glucuronide conjugate and to what extent other closely related steroids are metabo-

\footnotetext{
* Submitted for publication June 4, 1963; accepted January 23, 1964.

Supported by a grant (A-180) from the National-Institute of Arthritis and Metabolic Diseases, U. S. Public Health Service.

$\dagger$ Present address: Department of Pediatrics, Detroit Receiving Hospital and Wayne State University, 1326 St. Antoine, Detroit 26, Mich.

1 The following trivial names have been used: testosterone, 17 $\beta$-hydroxy-4-androstene-3-one; dehydroepiandrosterone, $3 \beta$-hydroxy-5-androstene-17-one; androstenedione, 4-androstene-3,17-dione; $17 \alpha$-hydroxyprogesterone, $17 \alpha$-hydroxy-4-pregnene-3,20-dione.
}

lized to testosterone glucuronide. In addition, the metabolism of testosterone and the quantity excreted as unconjugated testosterone, as testosterone glucuronide, and as testosterone sulfate was studied.

\section{Methods}

1) Preparation of radioactive steroids. 4- $\mathrm{C}^{14}$-testosterone ${ }^{2}$ (SA, $71.43 \mu \mathrm{c}$ per $\mathrm{mg}$ ), 1,2- $\mathrm{H}^{3}$-testosterone (SA, $2.63 \mathrm{mc}$ per $\mathrm{mg}$ ), 4-C $\mathrm{C}^{14}-17 \alpha$-hydroxyprogesterone (SA, $43.48 \mu \mathrm{c}$ per $\mathrm{mg}$ ), $4-\mathrm{C}^{14}$-androstenedione (SA, $7.58 \mu \mathrm{c}$ per $\mathrm{mg}$ ), and $7 \alpha-\mathrm{H}^{3}$-dehydroepiandrosterone acetate (SA, $25.65 \mathrm{mc}$ per $\mathrm{mg}$ ) were used in this investigation. Before use, they were purified by paper chromatography (2).

2) Mode of injection of radioactive steroids and urine collections. In Table I, are listed some clinical data on the subjects used for this investigation. All injections were given intravenously, and the determination of the exact dose injected was calculated as previously described (3). The radioactive steroids were prepared in absolute ethanol and diluted with $0.9 \% \mathrm{NaCl}$ solution before iv administration. The injection usually lasted about 5 minutes. The number of counts per minute injected is shown in Tables II, III, and IV. After the injection of the radioactive tracer, urine was collected for 48 hours' in each experiment. All samples were frozen and stored at $-20^{\circ} \mathrm{C}$ until the analyses were done.

3) Preparation of extracts. An 8- to 24-hour sample of each urine collection was used. The urine was extracted 3 times with an equal volume of ether, and this extract will be referred to as the "unconjugated fraction." From 97 to $100 \%$ of radioactive testosterone added to crude urine is recovered after three extractions with equal volumes of ether.

To the urinary residue was added $1.0 \mathrm{ml}$ of $2 \mathrm{M}$ acetate buffer and 7,500 $\mathrm{U}$ of liver $\beta$-glucuronidase (ketodase) for each $10 \mathrm{ml}$ of urine. After adjusting the $\mathrm{pH}$ to 4.6 with $70 \%$ sulfuric acid, the urine was incubated at $37^{\circ} \mathrm{C}$ for 72 hours. Extraction was then carried out 3 times with equal volumes of ether. This extract represented the "glucuronide fraction."

After removal of glucuronide conjugates, the urine

2 All radioactive steroids were obtained from New England Nuclear Corp., Boston, Mass. 
TABLE I

Experimental subjects

\begin{tabular}{|c|c|c|c|}
\hline Subjects & Sex & Age & Diagnosis \\
\hline & & yrs & \\
\hline S.H. & M & 23 & Normal \\
\hline B.B. & M & 24 & Normal \\
\hline R.C. & $\mathbf{M}$ & 27 & Normal \\
\hline W.H. & $\mathrm{M}$ & 29 & Normal \\
\hline J.F. & M & 29 & Normal \\
\hline A.C. & M & 34 & Normal \\
\hline C.M. & $\mathbf{M}$ & 38 & Normal \\
\hline S.Bo. & $\mathrm{F}$ & 19 & Normal \\
\hline A.N. & $\mathrm{F}$ & 20 & Normal \\
\hline L.F. & $\mathrm{F}$ & 20 & Normal \\
\hline S.B. & $\mathrm{F}$ & 21 & Normal \\
\hline J.D. & $\mathrm{F}$ & 23 & Normal \\
\hline A.M. & $\mathrm{F}$ & $0 \frac{1}{12}$ & C.A.H., simple* \\
\hline M.L. & $\mathrm{F}$ & $1^{12}$ & C.A.H., simple \\
\hline R.P. & $\mathrm{M}$ & $2 \frac{1}{2}$ & Hepatoma, virilizing \\
\hline M.G. & $\mathrm{F}$ & $3 \frac{1}{2}$ & $\begin{array}{l}\text { Adrenal tumor, masculinizing } \\
\text { and feminizing }\end{array}$ \\
\hline M.J. & M & $3 \frac{1}{2}$ & C.A.H., simple \\
\hline M.R. & $\mathrm{F}$ & 4 & C.A.H., simple \\
\hline L.R. & $\mathrm{F}$ & $5 \frac{1}{4}$ & C.A.H., simple \\
\hline V.C. & $\mathrm{M}$ & $6 \frac{1}{2}$ & C.A.H., simple \\
\hline C.L. & $\mathrm{F}$ & 14 & $\begin{array}{l}\text { C.A.H., simple; oophero- } \\
\text { hysterectomy, bilateral }\end{array}$ \\
\hline H.G. & M & 14 & $\begin{array}{l}\text { Eosinophilic adenoma of } \\
\text { pituitary }\end{array}$ \\
\hline P.C. & M & $14 \frac{1}{2}$ & Klinefelter's syndrome \\
\hline B.Bu. & $\mathrm{F}$ & 15 & C.A.H., simple \\
\hline J.C. & $\mathrm{F}$ & 15 & $\begin{array}{l}\text { Bilateral polycystic ovaries; } \\
\text { arrhenoblastoma of left ovary }\end{array}$ \\
\hline C.J. & F & 20 & $\begin{array}{l}\text { Gonadal dysgenesis; chromatin } \\
\text { negative }\end{array}$ \\
\hline B.H. & $\mathrm{F}$ & 23 & C.A.H., simple \\
\hline E.B. & $\mathrm{F}$ & 28 & Stein-Leventhal syndrome \\
\hline I.H. & $\bar{F}$ & 34 & Acromegaly \\
\hline
\end{tabular}

* Congenital adrenal hyperplasia, simple virilizing form. residue was subjected to solvolysis (4). The urine residue was adjusted to $2 \mathrm{~N}$ by the addition of concentrated sulfuric acid and then extracted with an equal volume of ethyl acetate. The ethyl acetate was incubated at $37^{\circ} \mathrm{C}$ for 24 hours. This extract was called the "sulfate fraction." The radioactivity of each of the three fractions was determined.

4) Isolation of testosterone. The whole procedure for the isolation of testosterone has been described in detail elsewhere (1). In brief, the ether extracts of the unconjugated and glucuronide fractions were washed with sodium hydroxide and distilled water. The ethyl acetate extract representing the sulfate fraction was washed once with a half volume of $10 \%$ sodium bicarbonate in distilled water and once with a half volume of distilled water (4). All the extracts were then evaporated to dryness and chromatographed on a florisil column before gradient elution alumina chromatography and paper chromatography in the Bush 1 and 3 solvent systems (2). After the final paper chromatography, the testosterone area was eluted, and the effluent was evaporated to dryness. The residue was then assayed for radioactivity.

In all the experiments, a known amount of radioactive testosterone was added to the various urinary extracts for the calculation of recovery. When the experimental subject had received a steroid labeled with tritium, 4- $\mathrm{C}^{14}$-testosterone was added; $1,2-\mathrm{H}^{8}$-testosterone was used in cases where a $\mathrm{C}^{14}$ steroid had been administered. The recovery through the entire procedure ranged from 58 to $76 \%$.

5) Radioactivity determination. The total radioactivity in crude urine was determined as described by Flood and associates (5). The radioactivity of the unconjugated, glucuronide, and the sulfate fractions was determined by using a micromil window flow-counter as

TABLE II

Radioactivity in various urinary fractions after injection of 4-C $C^{14}$-testosterone in normal adult males and females*

\begin{tabular}{|c|c|c|c|c|c|c|c|c|c|}
\hline \multirow[b]{2}{*}{ Subjects } & \multirow[b]{2}{*}{ Sex } & \multirow[b]{2}{*}{$\underset{\text { injected }}{\mathrm{cpm}}$} & \multirow{2}{*}{$\begin{array}{c}\text { Crude } \\
\text { urine } \\
0-48 \mathrm{hr}\end{array}$} & \multicolumn{2}{|c|}{$\begin{array}{l}\text { Unconjugated } \\
\text { fraction }\end{array}$} & \multicolumn{2}{|c|}{$\begin{array}{c}\text { Glucuronide } \\
\text { fraction }\end{array}$} & \multicolumn{2}{|c|}{ Sulfate fraction } \\
\hline & & & & Total & $\begin{array}{c}\text { Testos- } \\
\text { terone }\end{array}$ & Total & $\begin{array}{c}\text { Testos- } \\
\text { terone }\end{array}$ & Total & $\begin{array}{l}\text { Testos- } \\
\text { terone }\end{array}$ \\
\hline $\begin{array}{l}\text { W.H. } \dagger \\
\text { W.H. }\end{array}$ & $\mathbf{M}$ & $1,398,620$ & 75 & 0.437 & 0.000 & 33.69 & $\begin{array}{l}0.167 \\
0.152\end{array}$ & 19.21 & 0.004 \\
\hline B.B. & $\mathbf{M}$ & $1,406,830$ & 81 & 0.364 & & 46.94 & 1.880 & 9.58 & 0.022 \\
\hline S.H. & $\mathbf{M}$ & $1,383,890$ & 82 & 0.212 & & & 1.419 & 14.28 & 0.069 \\
\hline R.C. & $\mathbf{M}$ & $1,392,600$ & 80 & 0.887 & & 41.43 & 1.176 & 5.73 & 0.049 \\
\hline \multicolumn{2}{|c|}{ Mean value } & & 79.5 & 0.475 & & 40.69 & 1.158 & 12.20 & 0.036 \\
\hline A.N. & $\mathrm{F}$ & $1,364,320$ & 75 & 0.379 & 0.003 & 44.89 & 0.778 & 9.11 & 0.045 \\
\hline S.B. & $\mathrm{F}$ & $1,367,130$ & 65 & 0.348 & 0.002 & 25.60 & 0.693 & & \\
\hline J.D. & $\mathrm{F}$ & $1,354,100$ & 73 & 0.396 & 0.001 & & 0.589 & & \\
\hline L.F. & $\mathrm{F}$ & $1,198,440$ & 74 & 0.252 & 0.007 & 28.28 & 0.737 & 11.45 & 0.014 \\
\hline S.Bo. & $\mathrm{F}$ & $1,381,850$ & 78 & 0.394 & 0.007 & 38.53 & 1.067 & 14.70 & 0.039 \\
\hline \multicolumn{2}{|c|}{ Mean value } & & 73.0 & 0.354 & 0.004 & 34.33 & 0.773 & 11.75 & 0.033 \\
\hline
\end{tabular}

* All results expressed as percentages of dose injected.

$\dagger$ Repeat determinations on same urine collection.

$\ddagger 0$ to 24 -hour collection. 
TABLE III

Radioactivity in various urinary fractions after injection of $4-C^{14}$-testosterone in male and female patients*

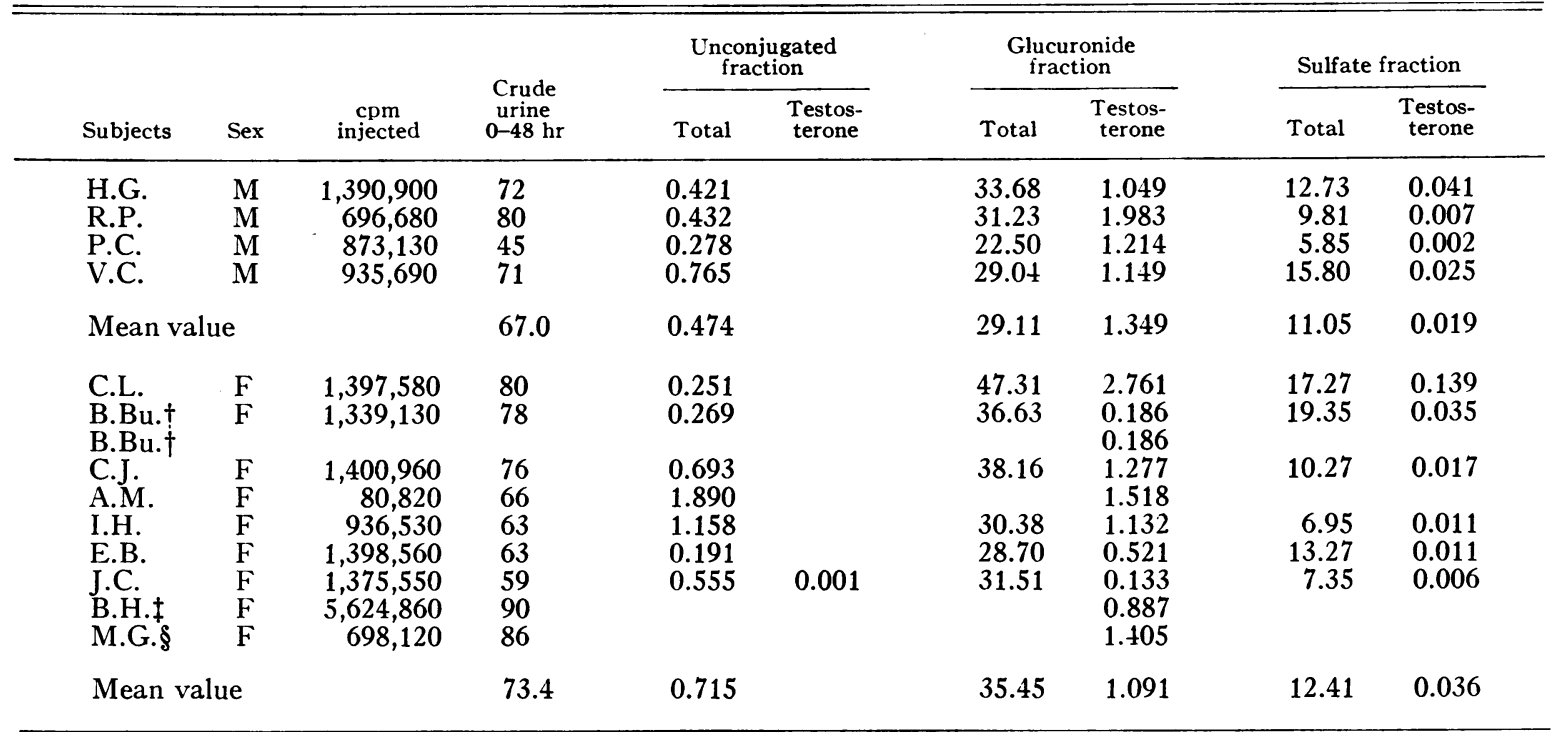

* All results expressed as percentages of dose injected.

$\uparrow$ Repeat determination on same urine collection.

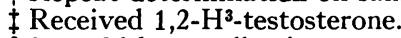

\$ 0 - to 36 -hour collection.

TABLE IV

Radioactivity in urine as testosterone in glucuronide fraction after injection of steroids other than testosterone*

\begin{tabular}{|c|c|c|c|c|}
\hline Subjects & Sex & $\underset{\text { injected }}{\mathrm{cpm}}$ & $\begin{array}{c}\text { Crude } \\
\text { urine } \\
0-48 \\
\mathrm{hr}\end{array}$ & $\begin{array}{l}\text { Testos- } \\
\text { terone } \\
\text { in glu- } \\
\text { curonide } \\
\text { fraction }\end{array}$ \\
\hline \multicolumn{5}{|c|}{$4-\mathrm{C}^{14}-17 \alpha-\mathrm{OH}$-progesterone } \\
\hline $\begin{array}{l}\text { J.F., normal } \\
\text { A.C., normal } \\
\text { M.J., patient } \\
\text { B.Bu., patient } \\
\text { M.R., patient } \\
\text { L.R., patient }\end{array}$ & $\begin{array}{l}M \\
M \\
M \\
F \\
F \\
F\end{array}$ & $\begin{array}{r}1,156,260 \\
1,151,670 \\
360,450 \\
1,143,210 \\
383,300 \\
382,930\end{array}$ & $\begin{array}{l}66 \\
89 \\
70 \\
74 \\
78 \\
87\end{array}$ & $\begin{array}{l}0.000 \\
0.004 \\
0.002 \\
0.001 \\
0.000 \\
0.003\end{array}$ \\
\hline \multicolumn{5}{|c|}{ 4-C $\mathrm{C}^{14}$-androstenedione } \\
\hline $\begin{array}{l}\text { C.M., normal } \\
\text { A.C., normal } \dagger \\
\text { A.C., normal } \dagger \\
\text { B.Bu, patient } \dagger \\
\text { B.Bu., patient } \dagger\end{array}$ & $\begin{array}{l}\mathrm{M} \\
\mathrm{M} \\
\mathrm{F}\end{array}$ & $\begin{array}{l}1,151,560 \\
1,187,380 \\
1,253,520\end{array}$ & $\begin{array}{l}91 \\
91 \\
79\end{array}$ & $\begin{array}{l}0.186 \\
0.560 \\
0.643 \\
0.028 \\
0.025\end{array}$ \\
\hline \multicolumn{5}{|c|}{$7 \alpha$ - $\mathrm{H}^{3}$-dehydroepiandrosterone acetate } \\
\hline $\begin{array}{l}\text { C.M., normal } \\
\text { A.C., normal } \\
\text { V.C., patient } \\
\text { M.L., patient }\end{array}$ & $\begin{array}{l}\mathrm{M} \\
\mathrm{M} \\
\mathrm{M} \\
\mathrm{F}\end{array}$ & $\begin{array}{r}1,279,560 \\
1,391,710 \\
1,280,060 \\
626,890\end{array}$ & $\begin{array}{l}77 \\
76 \\
53 \\
51\end{array}$ & $\begin{array}{l}0.021 \\
0.052 \\
0.040 \\
0.010\end{array}$ \\
\hline
\end{tabular}

* All results expressed as percentages of dose injected. $\dagger$ Repeat determinations on same urine collection. previously described (3). The samples were counted for a period of time sufficiently long to obtain $95 \%$ accuracy, and correction was made for quenching.

Radioactivity content of the eluates from the final paper chromatogram containing both $\mathrm{H}^{3}$ and $\mathrm{C}^{14}$ was counted on a Packard automatic Tri-Carb scintillation spectrometer. The attenuators were set at the 2 mark, and the discriminator was set at 10 to 50 . The samples were counted at high voltages, 920 and 1,320 v. With these experimental conditions no tritium was detected at 920 v. Proper correction was made for the interference of $\mathrm{C}^{14}$ at $1,320 \mathrm{v}$. No correction was made for quenching on the paper eluates, since on the few samples when it was done, it was found unnecessary.

\section{Results}

1) Crude urine. The excretion of radioactivity in the urine of four normal men and five normal women after injection of $4-\mathrm{C}^{14}$-testosterone was in the range of 65 to $82 \%$ of the injected dose with a mean value of $76 \%$ (Table II), whereas in the patients it ranged from 45 to $90 \%$ with a mean value of $70 \%$ (Table III).

The mean excretions of radioactivity in the urine after the injection of $4-\mathrm{C}^{14}-17 \alpha$-hydroxyprogesterone, 4- $\mathrm{C}^{14}$-androstenedione, and $7 \alpha-\mathrm{H}^{3}$ - 
dehydroepiandrosterone acetate were 77,87 , and $64 \%$, respectively (Table IV). The radioactivity excreted in the urine of normal subjects did not differ significantly from that of patients. The relatively poor recoveries of radioactivity in urine after the injection of $7 \alpha-\mathrm{H}^{3}$-dehydroepiandrosterone acetate in patients VC and ML may have resulted from the difficulty in accurately collecting urine in small children.

2) Radioactivity contained in the various urinary fractions after radioactive testosterone injection. The amounts of radioactivity (expressed as percentages of the injected dose) recovered in the various urinary fractions from normal subjects and patients who had received labeled testosterone are shown in Tables II and III. The unconjugated fractions constituted an insignificant part of the radioactivity excreted while the glucuronide fraction and the sulfate fraction accounted for practically all of the radioactivity recovered. A significant amount of radioactivity was not extracted from the urine.

3) Radioactivity as testosterone contained in the various urinary fractions after radioactive testosterone injection (Tables II and III). The amount of radioactive testosterone found in the unconjugated fraction ( 0 to $0.007 \%$ of the injected dose) and in the fraction after solvolysis ( 0.002 to $0.139 \%$ of the injected dose) was very small.

In contrast, the amount of radioactive testosterone in the glucuronide fraction was much greater although representing a small fraction of the dose injected. The percentage of the injected radioactive testosterone excreted as testosterone glucuronide in the four normal males ranged from 0.152 to $1.880 \%$ with a mean value of $1.158 \%$. In the five normal females the excretion ranged from 0.589 to $1.067 \%$ with a mean value of $0.773 \%$. The mean percentage values in male and female patients were 1.349 and $1.091 \%$, respectively.

4) Radioactivity as testosterone contained in the glucuronide fraction after $4-C^{14}-17 \alpha$-hydroxyprogesterone injection (Table IV). In one subject, no radioactivity was found in the final eluate corresponding to testosterone, whereas in the five other subjects the radioactivity was extremely small. It was impossible to determine whether these small amounts of radioactivity were due to isotopic testosterone or to recontamination.

5) Radioactivity as testosterone contained in the glucuronide fraction after 4-C $C^{14}$-androstenedione injection (Table IV). The percentage of injected radioactive androstenedione converted to testosterone glucuronide varied in the three subjects studied. In the two normal subjects $0.601 \%$ and $0.186 \%$ of the injected dose was converted to testosterone, whereas in the patient studied the percentage converted was 0.028 .

6) Radioactivity as testosterone contained in the glucuronide fraction after $7 \alpha-H^{3}$-dehydroepiandrosterone acetate injection (Table IV). The radioactivity excreted as testosterone glucuronide was very small in both control subjects and in the two patients studied $(0.010$ to $0.052 \%$ of the injected dose).

\section{Discussion}

After 4-C ${ }^{14}$-testosterone administration, the major part of the injected radioactivity appeared in the urine in 48 hours. About $50 \%$ of this radioactivity could be extracted after different hydrolytic procedures with the greatest part of it being present in the glucuronide fraction (Tables II and III). These findings are similar to those of other investigators (6-9).

Our results also show that only a small percentage of the injected labeled testosterone was excreted in the urine as testosterone and that most of this was recovered after $\beta$-glucuronidase hydrolysis. Minimal amounts of radioactivity corresponding to testosterone were liberated after solvolytic procedures; the amounts of radioactivity were too small to establish that testosterone is excreted as a sulfate conjugate (Tables II and III). That testosterone is excreted in the urine as a glucuronide is supported by the data of other investigators (10-12).

Eighteen of the twenty-two subjects to whom radioactive testosterone was administered converted 0.5 to $2.0 \%$ of the injected dose to testosterone glucuronide with the exception of one normal subject and three patients. The percentage conversion in this normal subject was 0.15 ; in the three patients, two of whom had untreated congenital adrenal hyperplasia and one who had bilateral polycytic ovaries and an arrhenoblastoma 
of the left ovary, the percentage conversion was $2.761,0.186$, and 0.133 , respectively. The variability of the percentage conversion of testosterone to urinary testosterone glucuronide in the various subjects indicates that the measurement of testosterone excretion in any particular individual cannot give an estimate of the production rate of testosterone.

Minimal amounts of $17 \alpha$-hydroxyprogesterone were converted to testosterone glucuronide (Table IV). Fukushima and associates estimated the daily production of $17 \alpha$-hydroxyprogesterone to be $3 \mathrm{mg}$ for a normal male adult and between 240 and 280 for an adult patient with untreated congenital adrenal hyperplasia (13). The contribution, therefore, of $17 \alpha$-hydroxyprogesterone to urinary testosterone would be insignificant, even in patients with untreated congenital adrenal hyperplasia.

The peripheral conversion of dehydroepiandrosterone to urinary testosterone glucuronide was minimal in the subjects studied (Table IV). Vande Wiele, MacDonald, Bolte, and Lieberman estimated the daily secretion rates of dehydroepiandrosterone in normal male and female adults to be in the range of 15 to $50 \mathrm{mg}$ and 12 to $25 \mathrm{mg}$, respectively, and stated that this is an overestimation (14), since the adrenal gland apparently secretes dehydroepiandrosterone sulfate (15-18). Dehydroepiandrosterone, therefore, should not be expected to contribute significantly to urinary testosterone glucuronide in normal subjects.

The percentage of administered radioactive androstenedione converted to urinary testosterone glucuronide varied in the subjects studied (Table IV) but was significant in every case.

The secretion rate of a compound can be estimated by injecting a trace amount of the radioactive substance and by determining its specific activity or that of one of its metabolites in urine (19-20). In the case of testosterone, the specific activity of urinary testosterone could be used for such a calculation. For this technique to be valid, however, several assumptions must be satisfied, one of which is that no other substance contributes to the urinary metabolite studied. Our data showed that the contribution of $17 \alpha$-hydroxyprogesterone to urinary testosterone glucuronide was probably insignificant and that it would not alter the calculated secretion rate of testosterone. The percentage of dehydroepiandrosterone transformed to testosterone glucuronide was also minimal. The percentage of androstenedione converted to testosterone glucuronide was 0.186 and 0.601 in normal subjects compared with a mean of 1.1 for testosterone. Although the production rate of androstenedione in man is not known, this compound has been isolated from human adrenal vein blood (21) and from animal spermatic vein blood (22). It has also been detected in ovarian vein blood of some cases of Stein-Leventhal syndrome, arrhenoblastoma, and adrenal rest tumor of the ovary (23). Furthermore, androstenedione and testosterone are interconvertible in vitro in the presence of liver slices (24) or human red blood cells (25). If this compound is produced in significant amounts, it would invalidate the determination of the secretion rate of testosterone.

In addition to being secreted by a gland, a substance can also arise from the extraglandular metabolism of another compound. The total quantity of substance formed would then represent the total production of this substance. Vande Wiele, MacDonald, Gurpide, and Lieberman (18) have devised an elegant method for determination of the production rate of the four androgens of man that are interconvertible in the body: dehydroepiandrosterone sulfate, dehydroepiandrosterone, androstenedione, and testosterone.

It is reasonable to assume that the androgenicity of testosterone is directly related to the concentration of this steroid in blood. If some of the testosterone formed in the body did not reach the circulation before glucuronidation (as would be the case if a part of androstenedione produced was metabolized in the liver to testosterone glucuronide without release of circulating unconjugated testosterone), the testosterone production rate based on the specific activity of urinary testosterone glucuronide would have no physiological significance. Experimental designs that take into consideration the interconversion of the various androgens (18) would not alleviate this problem.

Mahesh and Greenblatt (26) have reported that androstenedione and dehydroepiandrosterone were metabolized in vivo to circulating testosterone, but the extent of this transformation is not known. 
Until more information is available on the metabolism of androstenedione, the significance of the estimation of the production rate of testosterone on the basis of the specific activity of urinary testosterone is open to question.

\section{Summary}

Various radioactive steroids were injected into normal subjects and patients to determine their contribution to urinary testosterone glucuronide.

Minimal amounts of dehydroepiandrosterone and 17-hydroxyprogesterone were metabolized to urinary testosterone glucuronide. The mean percentage conversion of androstenedione to testosterone glucuronide was $0.27 \%$ compared with 1.1 for testosterone.

In view of these findings, urinary testosterone is not a unique metabolite of testosterone and cannot be used for estimation of testosterone secretion rate. On the other hand, this metabolite can be used for the determination of testosterone production rate. A correlation between the latter and biological androgenicity remains to be established.

\section{References}

1. Camacho, A. M., and C. J. Migeon. Isolation, identification and quantitation of testosterone in the urine of normal adults and in patients with endocrine disorders. J. clin. Endocr. 1963, 23, 301.

2. Bush, I. E. Methods of paper chromatography of steroids applicable to the study of steroids and mammalian blood and tissues. Biochem. J. 1952, 50, 370.

3. Migeon, C. J., A. A. Sandberg, H. A. Decker, D. F. Smith, A. C. Paul, and L. T. Samuels. Metabolism of 4-C $\mathrm{C}^{14}$-cortisol in man: body distribution and rates of conjugation. J. clin. Endocr. 1956, 16, 1137.

4. Burstein, S., and S. Lieberman. Hydrolysis of ketosteroid hydrogen sulfates by solvolysis procedures. J. biol. Chem. 1958, 233, 331.

5. Flood, C., D. S. Layne, S. Ramcharon, E. Rossipal, J. F. Tait, and S. A. S. Tait. An investigation of the urinary metabolites and secretion rates of aldosterone and cortisol in man and a description of methods for their measurement. Acta endocr. (Kbh.) 1961, 36, 237.

6. Fukushima, D. K., K. Dobriner, and T. F. Gallagher. Studies with testosterone- $d$ in normal men. J. biol. Chem. 1954, 206, 845.

7. Fukushima, D. K., H. L. Bradlow, K. Dobriner, and T. F. Gallagher. The fate of testosterone in- fused intravenously in man. J. biol. Chem. 1954, 206, 863.

8. Sandberg, A. A., and W. R. Slaunwhite, Jr. Metabolism of $4-\mathrm{C}^{14}$-testosterone in human subjects. I. Distribution in bile, blood, feces and urine. J. clin. Invest. 1956, 35, 1331.

9. Korenman, S. G., H. Wilson, and M. B. Lipsett. Testosterone production rates in normal adults. J. clin. Invest. 1963, 42, 1753.

10. Fishman, W. H., and H.-G. Sie. Formation of testosterone glucuronide by surviving liver slices. J. biol. Chem. 1956, 218, 335.

11. Edwards, R. W. H., and A. E. Kellie. The chromatographic separation of the glucuronides of urinary steroid ketones. Chemistry and Industry 1956, 1, 250.

12. Schubert, K., and K. Wehrberger. Isolierung von Testosterone aus Normalharn. Naturwissenschaften 1960, 47, 281.

13. Fukushima, D. K., H. L. Bradlow, L. Hellman, B. Zumoff, and T. F. Gallagher. Study of 17-hydroxyprogesterone-4- $\mathrm{C}^{14}$ in man. J. clin. Endocr. 1961, 21, 765.

14. Vande Wiele, R. L., P. C. MacDonald, E. Bolte, and S. Lieberman. Precursors of the urinary 11desoxy-17-ketosteroids: estimation of the secretory rate of dehydroisoandrosterone. J. clin. Endocr. 1962, 22, 1207.

15. Baulieu, E. Studies of conjugated 17-ketosteroids in a case of adrenal tumor. J. clin. Endocr. 1962, 22, 501.

16. Wallace, E. Z., and S. Lieberman. Biosynthesis of dehydroisoandrosterone sulfate by human adrenocortical tissue. J. clin. Endocr. 1963, 23, 90.

17. Migeon, C. J. In vitro sulfation of dehydroisoandrosterone (DHA) by preparations of virilizing adrenal tumors. Fed. Proc. 1963, 22, 468.

18. Vande Wiele, R. L., P. C. MacDonald, E. Gurpide, and S. Lieberman. Studies on the secretion and interconversion of the androgens. Recent Progr. Hormone Res. 1963, 19, 275.

19. Pearlman, W. H. (16- $\left.\mathrm{H}^{3}\right)$ Progesterone metabolism in advanced pregnancy and oophorectomized-hysterectomized women. Biochem. J. 1957, 67, 1.

20. Laumas, K. R., J. F. Tait, and S. A. S. Tait. The validity of the calculation of secretion rates from the specific activity of a urinary metabolite. Acta Endocr. (Kbh.) 1961, 36, 265.

21. Romanoff, E. B., P. Hudson, and G. Pincus. Isolation of hydrocortisone and corticosterone from human adrenal vein blood. J. clin. Endocr. 1953, 13, 1546.

22. West, C. D., V. P. Hollander, T. H. Kritchevsky, and $\mathrm{K}$. Dobriner. The isolation and identification of testosterone, $\Delta^{4}$-androstenedione-3,17, and 7-ketocholesterol from spermatic vein blood (abstract). J. clin. Endocr. 1952, 12, 915. 
23. Migeon, C. J. Androgens in human plasma in Hormones in Human Plasma, H. N. Antoniades, Ed. Boston, Little, Brown, 1960, p. 297.

24. Clark, L. C., Jr., and C. D. Kochakian. The in vitro metabolism of testosterone to $\Delta^{4}$-androstenedione-3,17, cis-testosterone, and other steroids by rabbit liver slices. J. biol. Chem. 1947, 170, 23.

25. Migeon, C. J., O. L. Lescure, W. H. Zinkham, and J. B. Sidbury, Jr. In vitro interconversion of
$16-C^{14}$-estrone and $16-C^{14}$-estradiol-17 $\beta$ by erythrocytes from normal subjects and from subjects with a deficiency of red cell glucose-6-phosphate dehydrogenase activity. J. clin. Invest. 1962, 41, 2025.

26. Mahesh, V. B., and R. B. Greenblatt. The in vivo conversion of dehydroepiandrosterone and androstenedione to testosterone in the human. Acta Endocr. (Kbh.) 1962, 41, 400. 